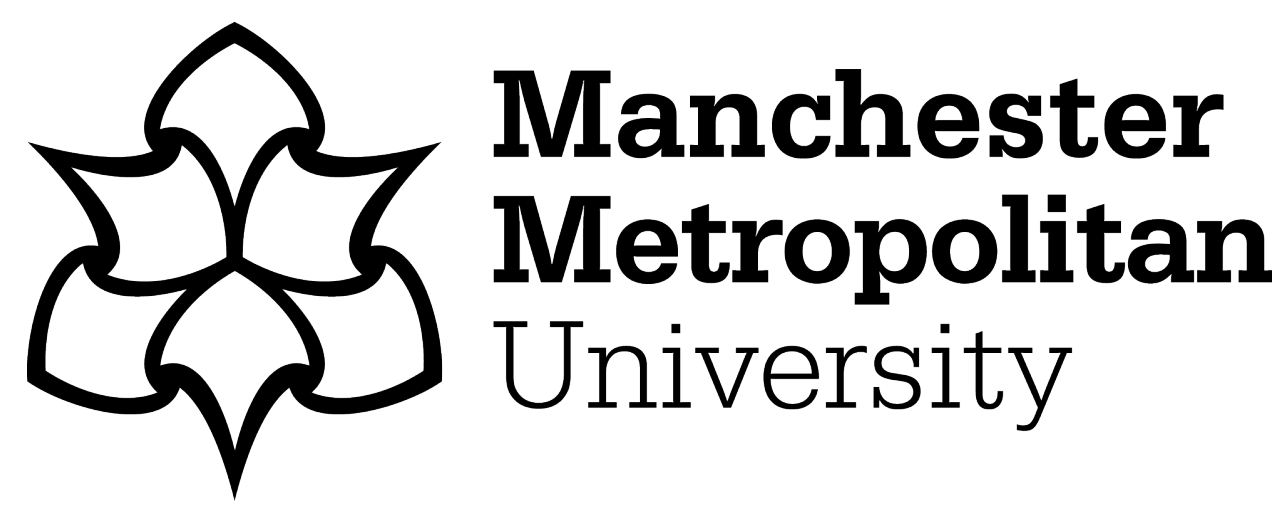

Keady, J, Campbell, S ORCID logoORCID: https://orcid.org/0000-00022920-7318, Barnes, H, Ward, R, Li, X, Swarbrick, C, Burrow, S and Elvish, R (2012) Neighbourhoods and dementia in the health and social care context: A realist review of the literature and implications for UK policy development. Reviews in Clinical Gerontology, 22 (2). pp. 150-163. ISSN 0959-2598

Downloaded from: https://e-space.mmu.ac.uk/625043/

Version: Accepted Version

Publisher: Cambridge University Press

DOI: https://doi.org/10.1017/S0959259811000268

Please cite the published version 


\title{
Neighbourhoods and dementia in the health and social care context: a realist review of the literature and implications for UK policy development
}

\author{
John Keady ${ }^{1}$, Sarah Campbell ${ }^{1}$, Helen Barnes ${ }^{1}$, Richard Ward ${ }^{1}, \mathrm{Xia} \mathrm{Li}^{2}$, Caroline Swarbrick ${ }^{1}$, \\ Simon Burrow ${ }^{1}$ and Ruth Elvish ${ }^{1}$ \\ ${ }^{1}$ Dementia and Ageing Research Team, School of Nursing, Midwifery and Social Work, University of Manchester \\ and ${ }^{2}$ Public Health Department, NHS Northamptonshire, UK
}

\section{Summary}

The National Dementia Strategy in England has performed an essential role in transforming health and social care services and improving the commissioning architecture. However, to date, little attention has been paid to understanding the ways in which the outdoor and built environment impacts and intersects with the lives of people with dementia and their carers. One way of better understanding the outdoor and built environment is through a focus on the 'neighbourhood' as this is an area of public policy where attempts are being made across disciplines to unpack its meanings, significance and identity. This paper adopts a realist review method to detail the key findings and messages from the body of work that links the experience of living with dementia to the neighbourhood. Our findings from this review are assimilated and defined/presented under three headings, namely: outdoor spaces, built environment, and everyday technologies. These headings and our definitions are not discrete properties and there is some overlap in content. We found no research that sets out to enquire about how people with dementia might define their neighbourhood or that explores everyday neighbourhood practices for those living with the condition. Emerging concepts such as citizenship and, in the UK, the Coalition Government advancement of the 'Big Society', promote a vision of civic responsibilities and networked, dementiacapable communities, but evaluation of such initiatives are virtually absent from the literature. The review did uncover some interesting and innovative research methods that extend neighbourhood working, such as the

Address for correspondence: John Keady, Professor of Older People's Mental Health Nursing, Dementia and Ageing Research Team, School of Nursing, Midwifery and Social Work, University of Manchester, University Place (Room 6.321), Oxford Road, Manchester M13 9PL, UK.

Email: John.Keady@manchester.ac.uk 'walking interview'. In order to develop a neighbourhood model for dementia, future research should examine the relationship and interaction between the neighbourhood as a social space and as a physical space alongside the active role of people with dementia as 'place-makers'.

Key words: dementia, neighbourhoods, outdoor spaces, built environment, public health.

\section{Introduction}

Blackman et al. ${ }^{1}$ argue that the 'public outdoor world is rarely conceived of as a dementia setting' (p. 361). This is an interesting observation as it has been known for some time that physical health impacts on the symptoms of dementia. For example, lifestyle (e.g. exercise, diet, smoking, alcohol) is associated with vascular health, ${ }^{2,3}$ and a number of vascular risk factors (e.g. diabetes, hypertension) are linked with an increased risk of Alzheimer's disease. ${ }^{4}$ Moreover, a positive environment helps to mitigate cognitive impairment and interacting with nature supports people with multi-sensory stimulation, which positively affects people's mental, emotional and spiritual well-being. ${ }^{5}$ In addition, the built environment is associated with physical activity, especially in promoting walking patterns amongst older adults. ${ }^{6}$

These observations are important as recent prevalence profiles in the United Kingdom (UK) have suggested that there are 750,000 people with dementia living with the condition, of whom two-thirds live at home with the support of carers and/or other support networks, such as relatives, friends and neighbours. ${ }^{7,8}$ Over the next 30 years as the UK population ages, the numbers of people living with dementia is expected 
to almost double to 1.4 million, ${ }^{9}$ an upward trajectory that is a world-wide phenomenon and one that requires a global response..$^{10,11}$ In part, this global response is being met through a push for earlier diagnosis and intervention with Alzheimer's Disease International recommending that an early diagnosis facilitates timely access to information, advice and support, thereby providing (in theory at least) effective intervention and care 'from the time of diagnosis to end of life' $\left({ }^{12} ;\right.$ p. 12). In England, and comparable to other countries across the developed world, such as Australia, France and Scotland, the challenge has also been met through the development of a National Dementia Strategy (NDS), ${ }^{9}$ which has the transcendent aim of enabling people with dementia to 'live well' with their condition. Linked to a service commissioning framework, the NDS $^{9}$ sets out 17 key outcomes (an 18th was later added, emphasizing the necessity to reduce/eradicate the prescription of anti-psychotic medication ${ }^{13}$ ) that provides benchmarks for quality service provision.

Whilst the $\mathrm{NDS}^{9}$ and, arguably, the direction of the recent Alzheimer's Disease International report, ${ }^{12}$ are clear about the responsibilities of health and social care services to meeting such important service-driven targets, both reports fail to adequately address the role of the community at large and the built environment in helping to support people with dementia and their carers as they go about their everyday lives. In the UK, this policy, practice and service vacuum has partly been met by the Conservative-Liberal Democratic Coalition Government and its advancement of the 'Big Society' where its three main themes revolve around social action, community empowerment and public service reform with a focus on localism, civic responsibility and the breaking-up of state monopolies to allow charities, social enterprises and community interest companies to provide public services. ${ }^{14}$

In a press launch to announce the vision and values of the 'Big Society', it was stated that 'devolving power down to neighbourhoods' was to be a central feature of activity (http://www. conservatives.com/News/News_stories/2010/03/ Plans_announced_to_help_build_a_Big_Society. aspx; accessed 27 October 2011). Interestingly, this neighbourhood theme was later picked up in a 'Dementia and the Big Society Think Tank' report by Goodchild and Rippon ${ }^{15}$ where the benefits of the 'Big Society' for people with dementia was acknowledged, particularly in viewing the person as an empowered citizen. However, these authors expressed some reservation about how to understand the 'boundaries of community and neighbourhood in this context' $\left({ }^{15} ;\right.$ p. 3$)$ and suggested that 'neighbourhoods might recognise that they have people living with dementia amongst them and want to be more inclusive of all community members' $\left({ }^{15} ;\right.$ p. 14$)$.

By undertaking a realist review ${ }^{16}$ of the literature on the areas intersecting within and between the neighbourhood, dementia and neighbourhood interventions, including population-based studies and public health approaches, this article attempts to gain further understanding about these boundaries and what research approaches may be helpful in undertaking neighbourhood research with people with dementia and their families.

\section{Methodology}

The review used a realist review method ${ }^{16}$ and primarily located the literature search around a UK focus in order to make the review and its implications targeted and manageable; however, to contextualize and embed this reporting, an international literature on neighbourhoods was also consulted. A realist review is designed to indicate 'what works for whom, in what circumstances, in what respects, and how' $\left({ }^{16}\right.$; p. 21), and can also provide insight into the structures, powers, generative mechanisms and tendencies of an area for intervention 'as a basis for developing research questions and designs' $\left({ }^{17} ;\right.$ p. 421). Research evidence accounted for in this review therefore includes qualitative and quantitative methodologies, including mixed methods designs and longitudinal studies.

Adapted from the work of Pawson et al. ${ }^{16}$ and O'Campo et al., ${ }^{18}$ this realist review followed the following steps:

- clarifying the scope of the review including its purpose, research questions, possible processes, and theories;

- identifying and collecting evidence, including identification of search terms and inclusion and exclusion criteria, and in the process refining theories and hypothesized mechanisms in an ongoing iterative process;

- appraising the evidence in terms of scientific rigour and what it contributes to the synthesis, 
identifying themes and extracting information for synthesis;

- synthesizing the evidence with theory, attending to the weight of evidence and to evidence supporting and questioning hypothesized processes and theories;

- formulating themes, processes and underpinning theory in relation to the purpose of the review.

The search terms adopted in the study are shown in Box 1, with these key terms used in various combinations with the following databases: PsycARTICLES, Cochrane Database systematic reviews, British Nursing Index and Archives 2010, Embase, Ovid Medline, Ovid Online, Social Care Online, Social Policy and Practice, Assia, Cinahl plus ebsco, and Web of Science.

\section{Box 1. Search terms}

\author{
Alzheimer[s]; cognition; dementia; vascular: \\ neighbourhood[s]; \\ ageing; \\ carer; \\ citizen[ship]; \\ community; \\ disadvantage; \\ education; \\ environment; \\ empowerment; \\ green space; \\ health: inequalities, promotion, public; \\ housing; \\ mental health; \\ neighbours; \\ older people; \\ outdoor[s]; \\ policy; \\ social: care, capital, exclusion, inequalities, \\ network; \\ transport; \\ walkability.
}

Inclusion criteria were specified as follows: UK papers from 1980 onwards in a health and social care context; literature only included where key words used in the search had a relationship with each other; international literature on neighbourhoods and dementia. All retrieved papers were read and sorted by members of the authorship
Table 1. Flow chart of included studies

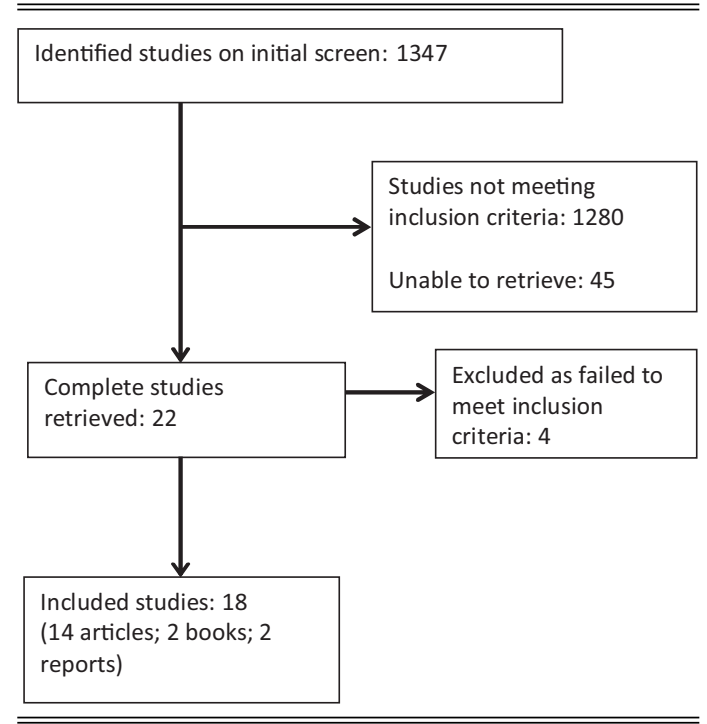

working in different combinations to complete this task. As Table 1 reveals, this search and sorting process led to the identification of 18 key studies which have informed the core of this realist review. The 18 key studies were thematically analysed by four members of the team (JK, RW, HB and SC) and were grouped into three headings that seemed to conceptually 'fit' and 'explain' the data in an accessible way, namely: outdoor spaces (which we defined as 'life outside the front door and/or the practicalities of getting out and about in the neighbourhood'); built environment (which we defined as 'the existence of dementia-friendly environments and/or how the environment can enable, or disable, people with dementia'); and everyday technologies (which we defined as 'how people with dementia interact/access technology outside the home and/or use technology to prepare to leave the home to engage with the outside world'). The 14 articles that informed this analysis and formed the substantive element of the core literature are explained in more detail in Table 2. However, we must point out that these headings and our definitions are not conceptually distinct but have some overlapping content. Before the article turns to address this literature, we will begin with a discussion on the meaning and definition of a neighbourhood.

\section{What is a 'neighbourhood'?}

In the UK, consensus about the meaning and constitution of a 'neighbourhood' is lacking. 


\begin{tabular}{|c|c|c|c|c|}
\hline & Reference & Aim & Sample & Methods \\
\hline$\overline{\mathrm{i}}$ & $\begin{array}{l}\text { Blackman T, Mitchell L, Burton E, Jenks M, } \\
\text { Parsons M, Raman S, Williams K. The } \\
\text { accessibility of public spaces for people } \\
\text { with dementia: a new priority for the } \\
\text { 'open city'. Disability Society 2003; 18: } \\
\text { 357-71. }\end{array}$ & $\begin{array}{l}\text { Reviews the literature on indoor design for } \\
\text { dementia, reports on research } \\
\text { investigating the accessibility of outdoor } \\
\text { environments and describes the use of } \\
\text { virtual reality technology to test outdoor } \\
\text { design with people with dementia }\end{array}$ & $\begin{array}{l}\text { Collates findings from more than } \\
\text { one study }\end{array}$ & Mixed methods \\
\hline ii & $\begin{array}{l}\text { Mitchell L, Burton E, Raman S, Blackman T, } \\
\text { Jenks M, Williams K. Making the } \\
\text { outside world dementia-friendly: design } \\
\text { issues and considerations. Environ } \\
\text { Planning B: Planning Design 2003; 30: } \\
\text { 605-32. }\end{array}$ & $\begin{array}{l}\text { Identifies the needs of older people with } \\
\text { dementia when using the outdoor } \\
\text { environment and suggests aspects of } \\
\text { design for making it dementia-friendly. } \\
\text { Reviews the design-for-dementia } \\
\text { literature }\end{array}$ & $\mathrm{n} / \mathrm{a}$ & $\begin{array}{l}\text { Literature review with a synthesis } \\
\text { of the advice for internal design } \\
\text { principles and considers their } \\
\text { applicability to the outdoor } \\
\text { environment }\end{array}$ \\
\hline iii & $\begin{array}{l}\text { Mitchell L, Burton E, Raman S. } \\
\text { Dementia-friendly cities: designing } \\
\text { intelligible neighbourhoods for life. J } \\
\text { Urban Design 2004; 9: 89-101. (Note: } \\
\text { study carried out as part of the EPSRC } \\
\text { EQUAL Consortium at the Wellbeing in } \\
\text { Sustainable Environments (WISE) at } \\
\text { Oxford Brookes University) }\end{array}$ & $\begin{array}{l}\text { To establish the importance of } \\
\text { (environmental) legibility for people with } \\
\text { dementia; to identify the design factors } \\
\text { that affect legibility for people with } \\
\text { dementia }\end{array}$ & $\begin{array}{l}20 \text { people with dementia and } \\
25 \text { people without dementia }\end{array}$ & $\begin{array}{l}\text { Interviews with a questionnaire } \\
\text { and photographs; accompanied } \\
\text { walks using an observation } \\
\text { schedule; environmental } \\
\text { analysis using a checklist of } \\
\text { environmental characteristics }\end{array}$ \\
\hline iv & $\begin{array}{l}\text { Mitchell L, Burton E. Neighbourhoods for } \\
\text { life: Designing dementia-friendly outdoor } \\
\text { environments. Quality Ageing: Policy } \\
\text { Practice Res 2006; 7: 26-33. }\end{array}$ & $\begin{array}{l}\text { Summary of the ESPRC funded EQUAL } \\
\text { project with recommendations for } \\
\text { outdoor design }\end{array}$ & $\begin{array}{l}\text { See Mitchell et al. (2004) above } \\
\text { (iii) }\end{array}$ & $\begin{array}{l}\text { See Mitchell et al. (2004) above } \\
\text { (iii) }\end{array}$ \\
\hline $\mathrm{v}$ & $\begin{array}{l}\text { Sheehan B, Burton E, Mitchell E. Outdoor } \\
\text { wayfinding in dementia. Dementia: Int J } \\
\text { Social Res Practice 2006; 5: 271-81. }\end{array}$ & $\begin{array}{l}\text { To investigate outdoor wayfinding } \\
\text { performance and identify which features } \\
\text { of the outdoor built environment are used } \\
\text { in wayfinding by people with dementia }\end{array}$ & $\begin{array}{l}13 \text { people with dementia (with } \\
\text { mild to moderate dementia and } \\
10 \text { control participants }\end{array}$ & $\begin{array}{l}\text { Accompanied walks with two } \\
\text { researchers }\end{array}$ \\
\hline vi & $\begin{array}{l}\text { Blackstock KL, Innes A, Cox B, Smith A, } \\
\text { Mason A. Living with dementia in rural } \\
\text { and remote Scotland: Diverse experiences } \\
\text { of people with dementia and their carers. } \\
\text { J Rural Studies 2006; 22: 161-76. }\end{array}$ & $\begin{array}{l}\text { To explore the relationship between the } \\
\text { experience of service provision for people } \\
\text { with dementia and their carers and their } \\
\text { rural location }\end{array}$ & $\begin{array}{l}45 \text { participants ( } 15 \text { people with } \\
\text { dementia and } 30 \text { carers) - based } \\
\text { in } 8 \text { rural areas of Scotland }\end{array}$ & $\begin{array}{l}\text { Focus groups and semi-structured } \\
\text { interviews }\end{array}$ \\
\hline vii & $\begin{array}{l}\text { Mitchell L. Neighbourhoods for life: the } \\
\text { outdoor environment. J Dementia Care } \\
\text { 2007; 15: 36-37. }\end{array}$ & $\begin{array}{l}\text { Report on the WISE Dementia Project for } \\
\text { practitioners }\end{array}$ & $\begin{array}{l}\text { See Mitchell et al. (2004) above } \\
\text { (iii) }\end{array}$ & $\begin{array}{l}\text { See Mitchell et al. (2004) above } \\
\text { (iii) }\end{array}$ \\
\hline
\end{tabular}




\begin{tabular}{|c|c|c|c|c|}
\hline & Reference & Aim & Sample & Methods \\
\hline viii & $\begin{array}{l}\text { Blackman T, Van Schaik P, Martyr A. } \\
\text { Outdoor environments for people with } \\
\text { dementia: an exploratory study using } \\
\text { virtual reality. Ageing Society } 2007 ; 27 \text { : } \\
811-25 . \text { (Note: research conducted as } \\
\text { part of the Virtual Reality Technology } \\
\text { and People with Dementia Study) }\end{array}$ & $\begin{array}{l}\text { To evaluate the validity and reliability of } \\
\text { virtual reality technology as a tool for } \\
\text { producing recommendations for physical } \\
\text { planning and design practice }\end{array}$ & $\begin{array}{l}38 \text { participants with mild to } \\
\text { moderate dementia ( } 19 \text { men and } \\
19 \text { women) aged } 71-84 \text { years }\end{array}$ & $\begin{array}{l}\text { Assessment of walks taken in a } \\
\text { real world environment } \\
\text { followed by a virtual 'walk' } \\
\text { through a simulated } \\
\text { environment }\end{array}$ \\
\hline ix & $\begin{array}{l}\text { Van Schaik P, Martyr A, Blackman T, } \\
\text { Robinson J. Involving persons with } \\
\text { dementia in the evaluation of outdoor } \\
\text { environments. CyberPsychol Behav 2008; } \\
\text { 11: 415-24. }\end{array}$ & $\begin{array}{l}\text { Examining the barriers and facilitators to } \\
\text { functioning outdoors for people with } \\
\text { dementia using virtual reality technology } \\
\text { (VRT) and whether findings can be } \\
\text { generalized to real environments }\end{array}$ & As above (viii) & As above (viii) \\
\hline $\mathrm{x}$ & $\begin{array}{l}\text { Duggan S, Blackman T, Martyr A, } \\
\text { Van Schaik P. The impact of early } \\
\text { dementia on outdoor life: a 'shrinking } \\
\text { world'? Dementia: Int J Social Res } \\
\text { Practice 2008; 7: 191-204. }\end{array}$ & $\begin{array}{l}\text { To explore the use of the outdoor } \\
\text { environment by people with dementia }\end{array}$ & $\begin{array}{l}22 \text { people with mild to moderate } \\
\text { dementia and their carers }\end{array}$ & Semi-structured interviews \\
\hline $\mathrm{xi}$ & $\begin{array}{l}\text { Yevchak AM, Loeb SJ, Fick DM. Promoting } \\
\text { cognitive health and vitality: a review of } \\
\text { clinical implications. Geriatric Nurs } \\
\text { 2008; 29: 302-10. }\end{array}$ & $\begin{array}{l}\text { A review of the literature on cognitive } \\
\text { health to identify strategies for cognitive } \\
\text { health promotion and implications for } \\
\text { nursing practice }\end{array}$ & $\mathrm{n} / \mathrm{a}$ & Literature review \\
\hline xii & $\begin{array}{l}\text { Mitchell L, Burton E. Designing } \\
\text { dementia-friendly neighbourhoods: } \\
\text { helping people with dementia to get out } \\
\text { and about. J Integrated Care 2010; 18: } \\
\text { 12-19. }\end{array}$ & $\begin{array}{l}\text { Summary of the ESPRC funded EQUAL } \\
\text { project with recommendations for } \\
\text { outdoor design }\end{array}$ & $\begin{array}{l}\text { See Mitchell et al. (2004) above } \\
\text { (iii) }\end{array}$ & $\begin{array}{l}\text { See Mitchell et al. (2004) above } \\
\text { (iii) }\end{array}$ \\
\hline xiii & $\begin{array}{l}\text { Brittain KR, Corner L, Robinson L, Bond J. } \\
\text { Ageing in place and technologies of place: } \\
\text { the lived experience of people with } \\
\text { dementia in changing social, physical and } \\
\text { technological environments. Sociol } \\
\text { Health Illness 2010; 32: 272-87. }\end{array}$ & $\begin{array}{l}\text { Explores the meanings and lived } \\
\text { experiences of people with dementia in } \\
\text { relation to everyday technologies in } \\
\text { public spaces outside the home }\end{array}$ & $\begin{array}{l}\text { Four focus groups with a total of } \\
16 \text { people with dementia and } \\
\text { three carers }\end{array}$ & $\begin{array}{l}\text { Re-analysis of qualitative data } \\
\text { from two studies of the use of } \\
\text { technology to support people } \\
\text { with dementia in their everyday } \\
\text { outdoor activities based on } \\
\text { focus groups }\end{array}$ \\
\hline xiv & $\begin{array}{l}\text { Brorsson A, Öhman A, Lundberg S, } \\
\text { Nygård L. Accessibility in public space as } \\
\text { perceived by people with Alzheimer's } \\
\text { disease. Dementia: Int J Social Res } \\
\text { Practice 2011; 10: } 587-602 .\end{array}$ & $\begin{array}{l}\text { To illuminate the experiences of } \\
\text { accessibility in public space in people } \\
\text { with Alzheimer's disease }\end{array}$ & $\begin{array}{l}7 \text { informants aged } 55 \text { and above } \\
\text { (5 women and } 2 \text { men) }\end{array}$ & $\begin{array}{l}\text { All bar } 1 \text { informant were } \\
\text { interviewed twice. The first } \\
\text { interview explored the use of } \\
\text { outdoor spaces; the second } \\
\text { followed up on significant } \\
\text { points made }\end{array}$ \\
\hline
\end{tabular}


However, a cursory glance of the UK literature over the last 30 years or so suggests that, in amongst others, it is a term that has frequently appeared in discourses related to public policy, town planning, urban regeneration, social science, health and social care commissioning, local council decision-making and anthropology. ${ }^{19-21}$ The neighbourhood has also formed part of a professional (practice) discourse. For example, the Cumberlege Report on 'Neighbourhood Nursing' in the mid-1980s ${ }^{22}$ suggested that the 'best place' for patient care was within people's own communities; in other words, within a primary care setting. A decade later, Reinhard et al..$^{23}$ took this practice implication further by linking together 'neighbourhood nursing'-'public health''healthy communities' to provide a chain for nursing interventions spread across the life and community spectrum.

This connection of neighbourhoods to identified and identifiable local communities is reflected in a definition of a neighbourhood by Blackman. ${ }^{19}$ In this work, Blackman ${ }^{19}$ suggests that neighbourhoods are 'a walkable zone of experience' at the 'smallest significant socio-spatial scale of the societies of which they are part' (p. 2) and that the neighbourhood is 'a local boundaried space that holds within it various attributes that are both physical and social' (pp. 20-21). Indeed, in Blackman's book 'Placing Health', ${ }^{19}$ which uses complexity theory to understand the interrelationships within neighbourhoods, he explains that the neighbourhood remains the location where researchers can get 'close to the lives' of individuals due to the location of 'the home'. Miller $^{24}$ reinforces the significance of this microculture in relation to the neighbourhood and argues that 'the home' and 'the street' explain much about how people identify with, and construct meaning about, their neighbourhood.

In contrast to the micro-culture, policy makers continue to define the neighbourhood in statements about its 'geographical boundaries' which address issues of governance, administration and eligibility for state aid and provision. For instance, since the late 1990s, a UK policy focus on 'Neighbourhood Renewal' has specifically targeted neighbourhoods where concerns about health inequality, poverty and race relations require attention and redress. ${ }^{19}$ Accordingly, in a realist review on neighbourhoods and dementia, it is important to take these broad social and political perspectives onboard and we 
will begin to further unpack this understanding in the next section through a brief focus on social capital, personhood and citizenship, and public health interventions.

\section{Neighbourhoods and dementia: context and considerations}

\section{The role of social capital}

In recent times there has been a growing interest in social capital and it has become an important factor in neighbourhood research as a way of explaining the social relationships that are within societies or groups of people. ${ }^{25}$ Social capital can be described as consisting of the following seven domains: empowerment; participation; associational activity and common purpose; supporting networks and reciprocity; collective norms and values; trust; safety and belonging. ${ }^{26}$ Forrest and Kearns ${ }^{26}$ were particularly interested in the 'residential neighbourhood' and state that how a neighbourhood is experienced on an individual level will depend on variants such as class, race, ethnic group and 'where someone is in the life course' $\left({ }^{26} ;\right.$ p. 2141). Developing this further, Gray $^{27}$ provides an additional angle on social capital as it applies to older people where she defines it as 'the array of social contacts that give access to social, emotional and practical support' (p. 6). This definition points towards the potential emotional and practical support that can emanate from social networks in neighbourhoods, which includes frequent contact with neighbours.

Loss of social capital in economically deprived areas has been linked to feelings of lack of safety in the neighbourhood. ${ }^{28-32}$ Similarly, in other studies of 'neighbourhood walking' and a review of neighbourhoods and health, including physical activity, ${ }^{33}$ aspects of social capital associated with more advantaged neighbourhoods, such as a better external reputation, feelings of safety and belonging, trusting neighbours and availability and use of local amenities and parks, have been found to be important variables linked to higher rates of walking. ${ }^{33-35}$

\section{Personhood and citizenship}

Kitwood's work ${ }^{36,37}$ on person-centred care and personhood revolutionized the way people with dementia were viewed by society, cared for/about and had their personhood respected and valued. In his seminal text 'Dementia Reconsidered: the person comes first', Kitwood ${ }^{36}$ provided the following definition of personhood:

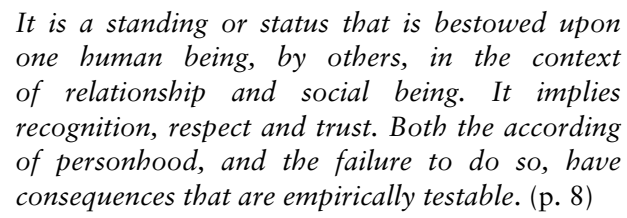

However, recent work has identified a limitation in this definition in that the approach and philosophical underpinnings remain at the level of the individual and fail to locate the person with dementia as an active participant in their community/neighbourhood. As proponents of this revised approach, Bartlett and O'Connor ${ }^{38,39}$ suggest that moving from a focus on personhood to citizenship broadens the lens for dementia practice and research and helps people with dementia connect to their wider society. Behuniak ${ }^{40}$ also argues that the citizenship approach itself needs to be augmented with a political model of dementia, one that is connected by a 'politics of empowerment and compassion’ (p. 237).

\section{Public health interventions}

In England, the report 'Healthy Lives, Healthy People' emphasizes a whole-systems approach to public health through effective collaboration between public health offices, the NHS and Adult Social Care with a high level vision 'to protect and improve the public's health, improving the health of the poorest, fastest' $\left({ }^{41} ; \mathrm{p} .52\right)$. Three key domains of public health practice are health improvement (e.g. inequalities), improving services (e.g. clinical effectiveness) and health protection (e.g. infectious diseases) ${ }^{42}$ and studies involving older people have repeatedly shown that positive changes to well-being can be made within disadvantaged neighbourhoods by, for example, improving housing and living conditions. ${ }^{43-45}$

Health promotion, as a core function of public health, is the process of enabling citizens to increase control over the determinants of health thereby improving their own health in order to reach a state of complete physical, mental and social well-being. ${ }^{46,47}$ Health promotion focuses 
on the positive, dynamic and empowering aspects of health, ${ }^{48}$ thus its fundamental element is human rights which is a basis for equity, empowerment and engagement. ${ }^{49}$ In dementia care, objective 1 of the NDS $^{9}$ develops this health promotion discourse by outlining the need to improve public and professional awareness about dementia and to reduce social exclusion and discrimination, issues that we will explore further in the next section.

\section{Neighbourhood and dementia: core literature}

\section{Outdoor spaces}

Mitchell and colleagues ${ }^{50}$ conducted one of the earliest UK studies to explore how people with dementia engage with outdoor environments and in which a social model of dementia is promoted. The research was informed by an extensive review of the literature on interior design and dementia, especially that of institutional settings. The authors note that internal design principles have been shown to have a positive effect on functional and cognitive abilities and on this basis argue for greater attention to outdoor design. The review identified six principles that are relevant to the design and planning of dementia-friendly outdoor environments, namely that such environments should be familiar, legible, distinctive, accessible, comfortable and safe. This is important as the outdoors has tremendous significance for older people in terms of their connections with neighbours, local shops and organizations and the natural world. ${ }^{51-53}$ For older people, being able to continue to use their local environment is significant in maintaining independence and interactions with others, as well as providing opportunities to exercise and promote physical well-being. ${ }^{54-56}$ There is also work that suggests that 'walking' helps to (at least) maintain cognitive functioning in those with dementia ${ }^{19,56}$ and that the practicalities of getting 'out and about' in neighbourhoods, such as through navigating local environments, plays a pivotal role in maintaining a person with dementia's sense of self and well-being. 1,19,57-61

Such environmental issues are important dimensions of neighbourhood living. The review on promoting cognitive health and vitality by Yevchak et al. ${ }^{62}$ clearly demonstrated the importance of older people maintaining social engagement, contacts and stimulation. Conversely, these authors found that older people with higher levels of perceived isolation and feelings of disconnection were twice as likely to experience more rapid cognitive decline in multiple functional domains compared with 'those individuals who perceived themselves to be supported by and connected to others' ${ }^{62} ;$ p. 307). Clare ${ }^{63}$ also found that meaningful relationships and stimulation maintained or increased the person's levels of awareness of self and environment.

Our review identified few studies which take account of everyday neighbourhood experiences and how these are affected by the onset of dementia. Overall, very little consideration has been given to social experiences tied to the neighbourhood of people with dementia or to the relationship of social networks to place and space. However, of the studies that do exist, Duggan et $a l .{ }^{56}$ report on an interview-based study involving 22 people living with dementia. Their discussion extends to briefly consider the nature of social encounters and interactions in the neighbourhood, highlighting the significance of informal encounters for people with dementia when they are 'out and about'. The authors develop the motif of a 'shrinking world' to capture the reported experience of outdoor life for the person with dementia, noting that 'symptoms [related to dementia] caused a reduction in the area in which they felt comfortable' $\left({ }^{56} ;\right.$ p. 198). The authors went on to explore the concerns of carers who were worried about their relative (with dementia) 'getting lost' or 'being distressed' when out alone, and also described the fear of 'becoming disorientated or confused'. In contrast, people with dementia simply talked about 'going out' $\left({ }^{56}\right.$; p. 197).

A local neighbourhood evaluation by Ward et $a .^{3}$ of an Age Concern peer support group for people with dementia in Salford, Greater Manchester found that public transport was raised many times by group members as a significant issue, especially as many of the participants were no longer able to drive since receiving their diagnosis. This evaluation also describes the importance for older people of feeling safe in their neighbourhood with their discourse often constructed around issues of risk. Day ${ }^{64}$ also highlights that the maintenance of a neighbourhood through its local amenities, services and social networks as important contextual considerations in promoting well-being. Aligned to this finding, Blackstock and colleagues ${ }^{65}$ explored life with dementia in 
rural Scotland and found that due to living in such close-knit communities, people who are the friends, neighbours and acquaintances of those living with dementia are also the same people who provide supportive services. On the one hand, when such services were reported as being 'helpful', it is reasonable to assume that in neighbourhoods where service provision is limited, strong interpersonal networks can act as a compensatory source of social capital. On the other hand, Blackstock et al. ${ }^{65}$ drew attention to a disadvantage of such close-knit communities in that when people with dementia were excluded from their networks, they had great difficulty in accessing the support they required.

Brittain et al. ${ }^{53}$ report two studies that examined how familiar and unfamiliar environments enable and disable those with memory loss, with a particular focus on how people with dementia engage with outdoor spaces and what the authors describe as 'technologies of place' (p. 283), i.e. the use of the physical landscape and other signage to ground orientation. The findings reinforce Duggan and colleagues ${ }^{56}$ conclusion that outside spaces can be anxiety-provoking (for both carers and people with dementia), leading to constraints on previous levels of outdoor activity. Both papers emphasize the fluid experience of place for people with dementia while Brittain et al. ${ }^{53}$ outline a process of becoming 'dislodged' from places once enjoyed. The research found that sometimes apparently minor alterations to 'technologies of place', such as bus routes, can inhibit a person with dementia from going out, thereby creating a sense of feeling 'out of place'. A similar conclusion was reached by Brorsson and colleagues, ${ }^{58}$ exploring the accessibility of outdoor spaces in Sweden. The study remarked upon the sensitivity of participants to 'subtle changes in landmarks in the public space that influenced their perceived accessibility' $\left({ }^{58}\right.$; p. 596). The meta-finding from the study was that accessibility to outdoor spaces is a constantly changing experience.

\section{Built environment}

The literature also reveals a small group of academics and professionals that have an interest in the built environment and people with dementia. A three-year research project undertaken by the WISE (Well-being in Sustainable Environments) Research Unit at Oxford Brookes
University between 2000 and 2003 examined how the outdoor environment could be made more 'dementia friendly' to enable people with dementia to be able to continue to use their neighbourhoods. ${ }^{61}$ This study utilized a number of methods to explore the needs of people with dementia: interviews, accompanied walks, and measuring the local environment using a checklist of environmental characteristics. The study describes how people with dementia spent their time 'going out', such as visiting the shops, post office or park, and it also identified people being more restricted to their local environment due to no longer driving and avoiding socially demanding situations or unfamiliar places. ${ }^{61}$ Similar to the findings of Duggan et al., ${ }^{56}$ the study explored issues of 'getting lost' for people with dementia. The project made some preliminary recommendations for ways to design dementiafriendly environments, suggesting the value of inclusive design. ${ }^{61}$

Interestingly, Blackman ${ }^{19}$ argues that neighbourhoods that cause stress and disable people from using them are denying the personhood of people with dementia by "not recognising and respecting individual personhood of all that live in the space' (p. 76). Negative neighbourhood aesthetics and negative aspects of the built environment that are traditionally associated with disadvantaged areas, are also important variables and significantly correlate in multi-level studies with reduced walking and lower levels of mental well-being. ${ }^{33,66}$ These losses are often associated with greater disablement in dementia. ${ }^{67}$ Gibson and colleagues ${ }^{5}$ have also reported that housing has impacted on well-being and quality of life for people with dementia through its connection to nature and access to the outdoors, which include opportunities for sensory stimulation and social interaction.

Another study concerned with way-finding and urban design by Blackman et al. ${ }^{57}$ and Van Schaik et $a .^{68}$ used a virtual environment to assess how different environmental features affected how people with dementia journeyed through a city setting. The research demonstrated that such technology can be used to support people with dementia in evaluating urban environments. The study found navigability, legibility, safety and environmental attractiveness to be key concerns for successful way-finding and enjoyment of outdoor spaces, with pedestrianized areas proving 
particularly popular with the research participants. A key message from this research ${ }^{68}$ was that real town centres offered relatively few obstacles for people with mild to moderate dementia, and that sometimes relatively straightforward changes, such as improvements to signage, could lead to measurable differences in way-finding and thereby improve quality of life and well-being.

Recent research into dementia and the outdoor environment is characterized by the inclusion of innovative, qualitatively-driven methods and recognition of the constraints of more traditional approaches to data-gathering. ${ }^{52,69}$ For instance, the use of accompanied walks in a study of wayfinding and dementia yielded valuable insights into the sensory experience of getting out and about for people with dementia. ${ }^{52,69}$ The research found that noise, smells and a multitude of visual stimuli had an influence on how participants negotiated journeys around their neighbourhood. ${ }^{52,69}$ This research also helped to identify the strategies that people with dementia used in order to navigate outdoor spaces and highlighted the importance of access to a local familiar neighbourhood for wellbeing.

\section{Everyday technologies}

Brittain et al. ${ }^{53}$ explored how everyday technologies mediate between people with dementia and their physical and social environment. These authors suggest that people with dementia will curtail their everyday practices in the outside environment due to anxiety and fear, with one person in their study describing how family worries about their safety led them to becoming more anxious about going out and about, despite that having previously been an important aspect of their identity. ${ }^{53}$ The study also states how a previously familiar and safe space may become an unfriendly space due to changing health and cognitive abilities. However, Brittain et al. ${ }^{53}$ also found that people with dementia do still continue to be active in their outside worlds, despite the challenges that this can bring, and that people with dementia use the physical landscape around them to find a way home.

Brorsson et al. $^{58}$ also highlight the issue of everyday technologies in their discussion of accessibility of public spaces. They highlight the growing trend for replacing human operatives with technology, for instance self-service check- outs in shops and supermarkets and the challenges that this presents for people with dementia, including having to learn and remember new practices for using such machinery. Similar problems were experienced when trying to book telephone appointments using digitized answering systems. Another recent development is the AT Guide (the AT standing for assistive technologies). The 'AT Guide: how technology can help you live well with dementia' (available at: http://www.atdementia.org.uk/; accessed 27 October 2011) is an online interactive tool that enables people with dementia to explore different aspects of daily living such as 'getting out and about'. By answering prompt questions on sub-topics such as 'keeping active', 'planning and preparation' and 'finding your way and keeping safe', information and advice is generated including, where relevant, suggestions for interacting with everyday technologies.

A recent way of integrating outdoors spaces, the built environment and everyday technologies has been explored through the development of Dementia Capable Communities which are seen to exist at three levels: dementia aware, friendly and capable. ${ }^{15}$ It is fair to say that the work on Dementia Capable Communities is in its infancy, but a recent exploratory report by 'Innovations in Dementia' that consulted with people with dementia both in community group and individual settings, suggested that people with dementia made use of the physical environment (such as through local facilities, support services, social networks and local groups) and that they kept in touch with their local communities through local groups, using local facilities, walking and using support services (full report available at: http://www.innovationsindementia.org.uk/; accessed 27 October 2011). Moreover, primed by recent (2011) funding by the Joseph Rowntree Foundation, the one-year 'Dementia Without Walls' project is looking at how to make York (in England) a good place to live with dementia (further information available at: http://www.jrf.org.uk/work/workarea/dementiaand-society; accessed 27 October 2011).

\section{Discussion}

The review revealed that interest in neighbourhoods goes hand-in-hand with an evolving debate 
on dementia. Earlier studies that have taken into account how people with dementia engage with the world beyond their front door have tended to draw upon a biomedical model with a focus on symptoms and behaviour. We have excluded such studies from the 'core' literature on neighbourhood on the grounds that they fail to acknowledge the role that the environment may play in promoting independence for people with dementia beyond the home.

Our focus in this paper is synchronized with an emerging shift to a social model of disability in dementia studies and the push towards promoting the rights of people with dementia as citizens. ${ }^{38,39}$ Current evidence shows that much of the cost of caring for people with dementia in the domestic home is placed upon the family carer, ${ }^{8}$ and this cost grows ever more significant if the person with dementia no longer has the independence to access their local neighbourhood. Interestingly, beyond Tim Blackman's ${ }^{19}$ public health-inspired definition of neighbourhood as 'a walkable zone of experience', we failed to identify a working definition of neighbourhood that might support dementia studies. According to our review, key aspects of such a definition would need to incorporate the fluidity of the relationship that people with dementia have to their localities and take account of the tensions that exist around when and how they access and make use of outdoor spaces. To date, we have found no research that sets out to enquire how people with dementia might define their neighbourhood or that explores everyday neighbourhood practices for those affected by the condition.

Interest in the neighbourhood and its relevance to dementia reflects a broader 'spatial turn' in the applied social sciences, while a concern to explore how people with dementia move about within these local spaces connects to the 'new mobilities paradigm' as identified by Sheller and Urry. ${ }^{70}$ Both developments can stimulate and expand the ways we think about and investigate the role of place and space in the lives of people with dementia. For instance, much of the existing work reviewed in this paper makes reference to a generic notion of 'outdoor space' with 'neighbourhood' remaining under-theorized and undifferentiated despite serving as a place with a distinct and dynamic relationship to the lives of the people who inhabit it. Yet it is clear that the local landscape is a shifting territory for people with dementia, both in terms of the meanings that it holds and the opportunities it offers. As Hall ${ }^{71}$ has argued in relation to his research using walking as a method for gathering data, local space is that through which lives take shape and the relationship between the geography of the town and the biographies of its people is one in which 'elements of biography are woven together with place(s)' (p. 581). Future research will need to find ways to look beyond outdoor space as a static backdrop to the lives of people with dementia.

One such newly emerging method is the 'walking interview', ${ }^{72}$ also known as the 'goalong interview'. ${ }^{73}$ As Mitchell and Burton ${ }^{59,61}$ have demonstrated, accompanying people with dementia as they make their way about their neighbourhood provides insights into embodied and sensory dimensions that would be unobtainable via traditional 'sedentary' methods. Arguably, 'sit-down interviews' serve only to 'separate participants from their routine experiences and practices in the participants' contexts' ${ }^{73} ;$ p. 267), whereas walking with participants can illuminate the practical and subjective experience of moving around a familiar zone of experience and the biographical connections it holds. Clearly, there is also scope for longitudinal research that takes us beyond the 'snap-shot' approach to gauging the relationship people with dementia have to their neighbourhoods, enabling a more in-depth understanding of how this alters with time.

A further challenge exists in finding ways to integrate our understanding of the neighbourhood as a physical or material space with that of a social space. It is noteworthy that to date few studies have sought in the dementia context to incorporate investigation of networks of support within these explorations of local spaces. Yet, at a time when formal services are undergoing significant change amid financial strictures, there is a pressing need to better understand the variety of sources of support and enablement for people with dementia that exist beyond specialist service provision. For instance, what role might neighbours play? How do local networks of friends and family co-ordinate themselves? And what significance, if any, is attached to the fleeting but often regular encounters with local shop-keepers, bank staff or supermarket workers? These questions concerning local relationships embedded within the neighbourhood present their own methodological challenges hitherto 
largely overlooked by the existing literature on neighbourhoods and dementia. They are, however, vital to any endeavour to develop a neighbourhood model for dementia.

Similarly, it is important to view care homes as an integral part of a neighbourhood. At present, the literature on care homes and people with dementia is predominantly focused on design and the (rightful) importance of gardens and sensory experiences for residents. ${ }^{74}$ In this context, 'going outside' for residents is largely constructed around accessing the care home's gardens and outside facilities, rather than what may well exist in the neighbourhood. Consequently, the expression and social positioning of residents with dementia as full and active members of their (own) neighbourhood is yet to be fully realized and perhaps this omission points a way forward to new opportunities for research and in generating more meaningful neighbourhood integration.

At present, it is clear that there is scope for further research to help build an evidence base for the role that neighbourhoods play in the lives of people with dementia. Key to this will be to move beyond a focus upon the physical attributes of 'outdoor spaces' to consider the neighbourhood as a social space and a source of both weak and strong ties that are meaningful and valued by people with dementia and their caregivers. We did not identify any studies that took account of the socio-economic profile of different neighbourhoods and their implications for living with dementia, or that addressed the diversity of the population with dementia and consequently how culture and identity might further shape the meaning and experience of local places and spaces. It is likely then, that future research that examines the relationship and interaction between the neighbourhood as a social space and as a physical space alongside the active role of people with dementia as 'place-makers' will make a valuable contribution to the development of a neighbourhood model for dementia.

\section{Conflicts of interest}

The authors have no conflicts of interest to declare.

\section{References}

1 Blackman T, Mitchell L, Burton E, Jenks M, Parsons M, Raman S, Williams K. The accessibility of public spaces for people with dementia: a new priority for the 'open city'. Disability Society 2003; 18: 357-71.

2 Price R, Keady J. Systematic review: role of health promotion in vascular dementia. $J$ Nursing Healthcare Chronic Illness 2010; 2: 88101.

3 Ward R, Campbell S, Keady J. Friends for Life: a local evaluation of the one year (2010-2011) peer support project for people with dementia in Salford. Manchester: The University of Manchester; 2011.

4 Mayeux R. The neighbourhood as the laboratory: Looking for answers by knocking on doors. Alzheimer Disease Assoc Disorders 2007; 21: 272-75.

5 Gibson G, Chalfont G, Clarke P, Torrington J, Sixsmith A. Housing and connection to nature for people with dementia: findings from the INDEPENDENT Project. J Housing Elderly 2007; 21: 55-72.

6 Gomez LF, Parra DC, Buchner D, Brownson RC, Sarmiento OL, Pinzon JD, Ardila M, Moreno J, Serrato M, Lobelo F. Built environment attributes and walking patterns among the elderly population in Bogotá. Am J Preventive Med 2010; 38: 592-99.

7 Alzheimer's Society. Dementia UK: A report into the prevalence and cost of Dementia, prepared by the Personal Social Services Research Unit (PSSRU) at the London School of Economics and the Institute of Psychiatry at Kings College London for the Alzheimer's Society. London: Alzheimer's Society; 2007.

8 National Audit Office. Improving Dementia Services in England - an Interim Report. London: The Stationery Office; 2010.

9 Department of Health. Living Well with Dementia: A National Strategy. London: Department of Health; 2009.

10 Luengo-Fernande R, Leal J, Gray A. The economic burden of dementia and associated research funding in the United Kingdom. London: Alzheimer's Research Trust; 2010.

11 Wimo A, Prince M. Alzheimer's Disease International World Alzheimer Report 2010: The Global Economic Impact of Dementia. Available at: http://www.alz.co.uk/research/files/ WorldAlzheimerReport2010.pdf (accessed 27 October 2011).

12 Prince M, Bryce R, Ferri C. World Alzheimer Report 2011: The benefits of early diagnosis and intervention. Available at: http://www.alz.co. uk/research/WorldAlzheimerReport2011.pdf (accessed 27 October 2011).

13 Banerjee S. The use of antipsychotic medication for people with dementia: Time for action $-A$ 
report for the Minister of State for Care Services. London: HMSO; 2009.

14 Cabinet Office. Building the Big Society. Available at: http://www.cabinetoffice.gov.uk/sites/ default/files/resources/building-big-society_0.pdf (accessed 27 October 2011).

15 Goodchild C, Rippon S. Dementia and the Big Society: Report from Think Tank 16th February 2011. London: Department of Health; 2011.

16 Pawson R, Greenhalgh P, Harvey G, Walshe K. Realist review - a new method of systematic review designed for complex policy interventions. J Health Services Res Policy 2005; 10 (suppl 1): 21-34.

17 Clegg S. Evidence-based practice in educational research: a critical realist critique of systematic review. Br J Sociol Education 2005; 26: 415-28.

18 O'Campo P, Kirst M, Schaefer-McDaniel N, Firestone M, Scott A, McShane K.

Community-based services for homeless adults experiencing concurrent mental health and substance use disorders: a realist approach to synthesizing evidence. J Urban Health Bulletin NY Acad Med 2009; 86: 965-89.

19 Blackman T. Placing health: neighbourhood renewal, health improvement and complexity. Bristol: The Policy Press; 2006.

20 Molyneux P. This is somewhere I want to stay. The Voluntary Sector's contribution to place-shaping. York: Joseph Rowntree Foundation; 2007.

21 Clark A. From neighbourhood to network: a review of the significance of neighbourhood in studies of social relations. Geography Compass 2009; 3: 1559-78.

22 Cumberlege J. Neighbourbood nursing - a focus for care. Report Community Nursing Rev. London: HMSO; 1986.

23 Reinhard SC, Christopher MA, Mason DJ, McConnell K, Rusca P, Toughill E. Promoting healthy communities through neighborhood nursing. Nursing Outlook 1996; 44: 223-28.

24 Miller D. The Comfort of Things. London: Polity Press; 2008.

25 De Silva MJ, McKenzie K, Harpham T, Huttly SR. Social capital and mental illness: a systematic review. J Epidemiol Community Health 2005; 59 : 619-27.

26 Forrest R, Kearns A. Social cohesion, social capital and neighbourhood. Urban Studies 2001; 38: 2125-43.

27 Gray A. The social capital of older people. Ageing Society 2009; 29: 5-31.

28 Ross CE. Neighborhood disadvantage and adult depression. J Health Social Behavior 2000; 41: 177-87.
29 Abbott P, Sapsford R. Living on the margins. Policy Studies 2005; 26: 29-46.

30 Kruger DJ, Reischl TM, Gee GC. Neighborhood social conditions mediate the association between physical deterioration and mental health. Am J Community Psychol 2007; 40: 261-71.

31 Ziersch AM, Baum FE, MacDougall C, Putland C. Neighbourhood life and social capital: the implications for health. Social Sci Med 2005; 60: 71-86.

32 Warr D, Feldman P, Tacticos T, Kelaher M. Sources of stress in impoverished neighbourhoods: insights into links between neighbourhood environments and health. Australian New Zealand J Public Health 2009; 33: 25-33.

33 Diez Roux AV, Mair C. Neighborhoods and health. Annals NY Acad Sci 2009; 1186: 125-45.

34 Wen M, Browning CR, Cagney KA. Poverty, affluence, and income inequality: neighborhood economic structure and its implications for health. Social Sci Med 2003; 57: 843-60.

35 Warr DJ. Social networks in a 'discredited' neighbourhood. J Sociol 2005; 41: 285-308.

36 Kitwood T. Dementia Reconsidered: The Person Comes First. Buckingham: Open University Press; 1997.

37 Kitwood T. The experience of dementia. Aging Mental Health 1997; 1: 13-22.

38 Bartlett R, O’Connor D. From personhood to citizenship: broadening the lens for dementia practice and research. J Aging Studies 2007; 21: 107-18.

39 Bartlett R, O’Connor D. Broadening the Dementia Debate: Towards social citizenship. Bristol: The Policy Press; 2010.

40 Behuniak SM. Toward a political model of dementia: power as compassionate care. J Aging Studies 2010; 24: 231-40.

41 Department of Health. Healthy Lives, Healthy People: our strategy for public health in England. London: Department of Health; 2010.

42 Faculty of Public Health. Working to improve the public's health: White paper response - Key points. London: Faculty of Public Health of the Royal Colleges of Physicians of the United Kingdom; 2011.

43 Crane M, Warnes AM. The outcomes of re-housing older homeless people: a longitudinal study. Ageing Society 2007; 27: 891-918.

44 Scharf T, Phillipson C, Smith AE, Kingston P. Growing older in socially deprived areas. Social exclusion later in life. London: Help the Aged; 2008.

45 Tribe R, Lane P, Heasum S. Working towards promoting positive mental health and well-being for older people from BME communities. Working with Older People 2009; 13: 35-40. 
World Health Organisation. Ottawa Charter for Health Promotion: First International Conference on Health Promotion. Ottawa: World Health Organisation; 1986.

47 World Health Organisation. The Bangkok Charter for Health Promotion in a Globalised World. Copenhagen: World Health Organisation; 2005.

48 World Health Organisation. A discussion document on the concepts and principles of health promotion. Health Promotion International 1986; 1: 73-76.

49 Eriksson M, Lindstrom B. A salutogenic interpretation of the Ottawa Charter. Health Promotion International 2008; 23: 190-99.

50 Mitchell L, Burton E, Raman S, Blackman T, Jenks M, Williams K. Making the outside world dementia-friendly: design issues and considerations. Environment and Planning B: Planning and Design 2003; 30: 605-32.

51 Burton E, Mitchell L. Inclusive Urban Design: streets for life. London: Elsevier; 2006. (E-book available at: http://issuu.com/filipesilva/docs/ ililbykhz2; accessed 27 October 2011).

52 Sheehan B, Burton E, Mitchell E. Outdoor wayfinding in dementia. Dementia: Int J Social Res Practice 2006; 5: 271-81.

53 Brittain KR, Corner L, Robinson L, Bond J. Ageing in place and technologies of place: The lived experience of people with dementia in changing social, physical and technological environments. Sociology Health Illness 2010; 32: 272-87.

54 Joseph Rowntree Foundation. The Older People's Inquiry: 'That little bit of help'. York: Joseph Rowntree Foundation; 2005.

55 Sugiyama T, Ward Thompson C. Outdoor environments, activity and the well-being of older people: conceptualising environmental support. Environment Planning 2007; 39: 1943-60.

56 Duggan S, Blackman T, Martyr A, Van Schaik P. The impact of early dementia on outdoor life: A 'shrinking world'? Dementia: Int J Social Res Practice 2008; 7: 191-204.

57 Blackman T, Van Schaik P, Martyr A. Outdoor environments for people with dementia: an exploratory study using virtual reality. Ageing Society 2007; 27: 811-25.

58 Brorsson A, Öhman A, Lundberg S, Nygård L. Accessibility in public space as perceived by people with Alzheimer's disease. Dementia: Int J Social Res Practice 2011; 10: 587-602.

59 Mitchell L, Burton E. Neighbourhoods for life: designing dementia-friendly outdoor environments. Quality Ageing: Policy, Practice Res 2006; 7: 26-33.

60 Mitchell L. Neighbourhoods for life: the outdoor environment. J Dementia Care 2007; 15: 36-37.

61 Mitchell L, Burton E. Designing dementia-friendly neighbourhoods: helping people with dementia to get out and about. I Integrated Care 2010; 18: 12-19.

62 Yevchak AM, Loeb SJ, Fick DM. Promoting cognitive health and vitality: a review of clinical implications. Geriatric Nursing 2008; 29: 302-10.

63 Clare L. Awareness in people with severe dementia: review and integration. Aging \& Mental Health 2010; 14: 20-32.

64 Day R. Theorizing growing and being older: connecting physical health, well-being and public health. Local environments and older people's health: dimensions from a comparative qualitative study in Scotland. Health Place 2008; 14: 299-312.

65 Blackstock KL, Innes A, Cox B, Smith A, Mason A. Living with dementia in rural and remote Scotland: diverse experiences of people with dementia and their carers. I Rural Studies 2006; 22: 161-76.

66 Berke EM, Gottlieb LM, Moudon AV, Larson EB. Protective association between neighborhood walkability and depression in older men. $\mathrm{J} \mathrm{Am}$ Geriatrics Soc 2007; 55: 526-33.

67 Cheston R, Bender M. Understanding Dementia: The Man with the Worried Eyes. London: Jessica Kingsley; 2009.

68 Van Schaik P, Martyr A, Blackman T, Robinson J. Involving persons with dementia in the evaluation of outdoor environments. CyberPsychology Behaviour 2008; 11: 415-24.

69 Mitchell L, Burton E, Raman S. Dementia-friendly cities: designing intelligible neighbourhoods for life. J Urban Design 2004; 9: 89-101.

70 Sheller M, Urry J. The new mobilities paradigm. Environ Planning A 2006; 38: 207-26.

71 Hall T. Footwork: moving and knowing in local space(s). Qualitative Res 2009; 9: 571-85.

72 Emmel N, Lark A. The methods used in Connected Lives: investigating networks, neighbourhoods and communities. London: ESRC National Centre for Research Method; 2009.

73 Carpiano R. Come take a walk with me: The 'Go-Along' interview as a novel method for studying the implications of place for health and well-being. Health Place 2009; 15: 263-72.

74 Chalfont G. Design for Nature in Dementia Care. London: Jessica Kingsley; 2007. 